\title{
The Analysis of Pragmatic Presupposition in English News Headlines
}

\author{
Tian Dong ${ }^{\mathrm{a}}$, Pingping Shao \\ School of Foreign Languages, North China Electric Power University, Hebei 071003, China. \\ ayuyanxue110@163.com, b1174681119@qq.com
}

\begin{abstract}
Faced with massive news information, news readers hardly have enough time or energy to read all of them. It is news headlines that help them get the most useful and interesting information out of the flooded information. As the essential part of news, headlines aim to summarize the main content in concise language, attract readers' eyeballs and stimulate the enthusiasm of reading, which requires headlines of conciseness, vividness and attractiveness. While, pragmatic presupposition can just make it satisfied, and it's an effective device for news headlines writing. This thesis attempts to analyze the application of pragmatic presupposition in English news headlines, providing a new perspective to appreciate news headlines and helping readers comprehend news headlines in a profound way.
\end{abstract}

Keywords: Pragmatic presupposition; English news headlines; application; functions.

\section{Introduction}

With the increasing communication in the information era, news plays a more and more significant role in our daily life. The news headline is the "eye" of the whole piece of news, through which readers could get the core of news. It's quite essential for readers to decide whether this piece of news is worth reading.

Due to the important role news headlines play in news, many scholars, at home and abroad, have done researches from different aspects. Firstly, some scholars direct their attention to the linguistic features of news headlines. For example, Hough points out some linguistic features that regularly appear in English news headlines. Secondly, some scholars probe into the translation of headlines. For instance, Tian Chuanmao and Ding Qing make a comparison between Chinese and English news headlines and further propose certain techniques for translation. Thirdly, attention is directed to the study of headlines on the basis of theories. For instance, Daniel Dor studies the headlines from the perspective of relevance theory, which presents the communicative function of headlines and the comprehension process in readers' cognition.

The study of news headlines has covered many fields, but the research on the presupposition in headlines has been hardly touched. This thesis attempts to analyze the application of pragmatic presupposition in English news headlines, which are mainly selected from China Daily in 2013. It mainly discusses how the pragmatic presupposition helps to realize conciseness, vividness, and attractiveness of news headlines. Through the analysis, it provides a new perspective to appreciate news headlines and helps readers comprehend news in a profound way.

\section{Pragmatic Presupposition Theory}

Presupposition, as a philosophical concept, appears in the book On Sense and Reference in 1892 at first, written by German philosopher Frege. Since the 1960s, presupposition has become substantial in definition, classification, features, strategies, functions and so on.

\subsection{The Definition of Presupposition.}

Presupposition is a controversial research field in linguistics, especially in semantics and pragmatics. In semantics, it refers to the semantic relation between two propositions of which one is the premise or pre-condition of the other (Chen 93). One important property of semantic presupposition is known as constancy under negation test. That is, the presupposition remains true even if the proposition presupposing it is negated. In pragmatics, however, presupposition is regarded as a sort of appropriate condition to perform speech acts effectively, or mutual knowledge shared by 
both speakers and addressees. While in daily communication, it is impossible and inadvisable to consider the sentences without the participants and particular situation of language use. Thus, the way of research gradually changes from semantics to pragmatics. Linguists have done lots of researches on this newly developed pragmatic theory in definition, classification, features, strategies, and so on.

There exist different understandings and definitions concerning about what pragmatic presupposition is. Some linguists may define it in a generalized way, while others may do in a narrow or specific way. Hitherto, there are three major viewpoints on pragmatic presupposition. Firstly, pragmatic presupposition is a sort of assumption made by speakers about the context while communicating. Just as He Ziran defines it "a presupposition relation that is sensitive to context and associated with speakers' (sometimes including addressees) belief, attitude and intention" (168). Secondly, pragmatic presupposition can be treated as a felicity condition for performing some speech acts or as the necessary condition that can endow a statement with social appropriateness. Fillmore understands pragmatic presupposition from the perspective of the felicity conditions. He defines it like this "an appropriate condition satisfied to effectively perform a certain illocutionary act through a sentence" (276). Thirdly, pragmatic presupposition is regarded as the mutual knowledge or common ground between speaker and hearer. This idea is showed by Levinson, regarding pragmatic presupposition as "An utterance A pragmatically presupposes a proposition B if A is appropriate only if B is mutually known by participants" (205).

\subsection{Characteristics of Pragmatic Presupposition.}

Many scholars have summarized several characteristics on the basis of its definitions. Since the property of common ground/mutual knowledge, felicity, subjectivity, and latency are well utilized to create news headlines, this thesis will mainly introduce the four main characteristics as follows.

Common ground or mutual knowledge. Common ground or mutual knowledge means that the assumed information or the context is known by both the speaker and the hearer and it is implied by speakers' utterances and can be understood by the hearer. In other words, communication can develop smoothly only when all the participants know what the utterance or proposition presupposed.

Felicity. According to Fillmore's understanding of pragmatic presupposition "an appropriate condition satisfied to effectively perform a certain illocutionary act through a sentence" (276), felicity can be treated as another property. Appropriateness is another name for it. Pragmatic presupposition is context-dependent and it is the pre-condition of speech act. That is to say, what is presupposed must be felicitous to situational context. For the same utterance may suggest different presuppositions in different contexts, the presupposition made by the speaker may not be understood by the hearer. Thus, the speaker should utter properly and make the hearer understand.

Subjectivity. Another property is subjectivity. It refers to a sort of subjective assumption about the context by the speaker. It's not necessarily true or correct. Presupposition can be objective facts, or assumed situation or facts held by the speaker. Leech once said that while uttering X, the speaker naturally think that $\mathrm{Y}$ is true. And because of the subjective beliefs and attitudes of the speaker, a pragmatic presupposition can be canceled in certain contexts (He 72).

Latency. The last important characteristic of pragmatic presupposition is latency, which is also called sneakiness. A proposition generally includes two sections: assertion and presupposition. The presupposed part is a kind of assumption and inference about the context by the speaker. It's not definitely true. Also, it's often hidden in words, so if people do not pay much attention, they will accept the presupposition as an assertion. Because of the latency of presupposition, it's easier for speakers to persuade addressees to accept their opinions unconsciously.

\section{The Analysis of News Headlines with Pragmatic Presupposition}

In the following part, this thesis analyses pragmatic presupposition in different forms of headlines, i.e. in sentences, in phrases, and in words.

\subsection{The Pragmatic Presupposition in Sentences.}

Sentences are common forms in news headlines. A number of presuppositions are embodied in them. Now let's study the presuppositions in declarative sentences and interrogative sentences. 
(1) NZ-China ties remain strong through dairy issues. (China Daily, August 22, 2013)

Common ground or mutual knowledge means that the presupposed information is shared by both the speaker and hearer, or communication will not continue smoothly. Here, "NZ" in the headline presupposes that the entity exists in the real world. More specifically, it's a country, New Zealand, in the world. The editor believes that readers have acquired the background knowledge to know what "NZ" stands for without excessive explanation. Due to common ground or mutual knowledge, the reader can understand the news easily.

The presupposed part is speaker's assumption and inference about the context. It's not expressed directly but hidden in words. In this headline, the verb "remain" indicates that the state is unchanged. Specifically, it means the state of NZ-China ties is stable. For readers who are familiar with their ties, they may recall some cooperative programs between the two countries in politics, economy, culture, and so on. All the presupposed information, implied in the words, fulfill the conciseness of language as well as enlarge the information quantity.

(2) Is there another scandal? (China Daily, June 14, 2013)

Interrogative sentences often generate suspense and doubt, attracting readers' attention. This effect is well presented by means of pragmatic presupposition. Levinson argues that questions carry the presuppositions "obtained by the appropriate existentially quantified variable" (184). At glance of the headline, readers have doubts that who has made a scandal and what the scandal is. Also, they may suspend whether another scandal is made or not. This headline leads to readers' curiosity and fulfills the headline's intention. On the other hand, the writer has well utilized latency of pragmatic presupposition. Although it is in the form of interrogative sentence, actually the news editor has already transferred presupposed information and their opinion to readers through positive tone. It's alternative that another scandal is made or not. When you're supposed to answer "yes" or "no" to the question, you have already unconsciously accepted the presupposition as an assertion. Thus, the audience is controlled by the speaker and follows the next part for the answer.

Interrogative sentences often generate suspense and doubts, so they draw readers' eyeballs. As a sort of assumed information, presupposition is latent, so readers will easily accept the presupposition as an assertion if they don't pay much attention.

\subsection{The Pragmatic Presupposition in Phrases.}

To save the space of a whole page, a number of headlines are written in the form of phrases. But for the satisfaction of the conciseness, vividness, and attractiveness of headline, pragmatic presupposition is often used to provide enough information for better understanding and attract readers' eyeballs. The examples are as follow.

(3) New information in Diana's death (China Daily, August 19, 2013)

The definite description "Diana's death" presupposes that Diana has died. The mutual knowledge or common ground is utilized. The editor believes that, as the famous princess of Wales, Diana and her death are well known. When readers read it, they may think of Diana about her death, and the reason of her death. Consequently, information quantity about Diana is surly increased.

Also, when the information provided by news headlines is conflicting with audience's background information, namely the presupposed information, audience will be eager to read the content of news. The headline tells readers that new information about Diana's death appears. Curiosity is generated unexpectedly. A person died fourteen years ago, maybe everything about her is slipped from people's memory. However, the headline tells readers that new information appears. Curiosity comes to readers and urges them to finish the reading for finding out the new information. The contrast between the presupposed information and the headline information increases the attractiveness of headlines.

\subsection{The Pragmatic Presupposition in Words.}

Acronyms always appear in English news headlines. It's the condensed written form consisting of the first letter of a series of words for certain meaning. They're applied to replace long or complex words, saving space and making structure balanced. There're three major types, including names of organizations, names of titles, and names of familiar objects. They're often used and readers are 
familiar with their meanings. Therefore, editors often make presupposed information in them. For instance:

(4) Britain to submit Syria resolution to UN (China Daily, August 28, 2013)

The pragmatic presupposition information in the acronyms is based on the common ground or mutual knowledge between the editor and the reader. For this, the conciseness and richness of headlines can be achieved. In headline, readers will presuppose that UN is some kind of an organization, even though they don't know what it really means. To readers familiar with UN, the knowledge about its aim, the group profile, the member states, will be activated. Even some readers can obtain the presupposition that UN, as a global organization, will do with Syria resolution in a fair way. All of the background information can help readers understand the news. On the other hand, based on the mutual knowledge of UN, the felicity condition for understanding the news is formed. Or, if the readers don't know what UN stands for, they will not understand the news. Namely, the presupposed information is the premise for understanding the news. According to the above analysis, the readers know that pragmatic presupposition in acronyms can not only simplify the language, saving space, but also it can provide extra information.

\section{Summary}

According to the analysis, it can be found that pragmatic presupposition plays a great role in news headlines. It can make news headlines concise as well as enlarge the information quantity for saving the space and enriching the meaning. Also, taking advantage of pragmatic presupposition can fulfill the attractiveness of the headlines or "mislead" the readers. All in all, pragmatic presupposition holds an important position in meeting the requirements of conciseness, vividness, and attractiveness of news headlines. Through this study, on the one hand, it can enrich the study of pragmatics. On the other hand, it provides a new perspective to appreciate news headlines and helps readers comprehend news in a profound way. At the same time, this study contributes to guiding the editor to design excellent news headlines by employing the linguistic device, pragmatic presupposition.

In brief, presupposition is essential for news headlines production and comprehension. It's worth everyone's attention and needs further research. To analyze the headlines from the perspective of pragmatic presupposition provides a new way for appreciating news.

\section{References}

[1] X.R. Chen, A New Course book in Pragmatics. Beijing: Foreign Language Teaching and Research Press, 2009.

[2] D. Dor, “On Newspaper Headlines as Relevance Optimizer”. Journal of Pragmatics, 6 (2003): 95-121.

[3] C. J. Fillmore, "Verb of Judging: an exercise in semantic description". Studies in Linguistic Semantics, 3 (1971): 273-90.

[4] G. A. Hough, News Writing. Boston: Houghton Mifflin Company, 1980.

[5] Levinson. Pragmatics. Cambridge: CPU, 1983.

[6] Chinadaily. 14 June 2013. 29 August 2013 〈http://www.chinadaily.com.cn/>.

[7] Q. Ding, C.M. Tian, The Analysis of the Differences and Similarities of English and Chinese News Headlines and Translation. Hexi College Journal, 6 (2003): 69-74.

[8] Z.R. He, An Introduction to Pragmatics, Changsha: Hunan Education Press, 1987. 